\title{
Revisiting "Steady-State" Monotonic and Cyclic Deformation: Emphasizing the Quasi-Stationary State of Deformation
}

\author{
HAËL MUGHRABI
}

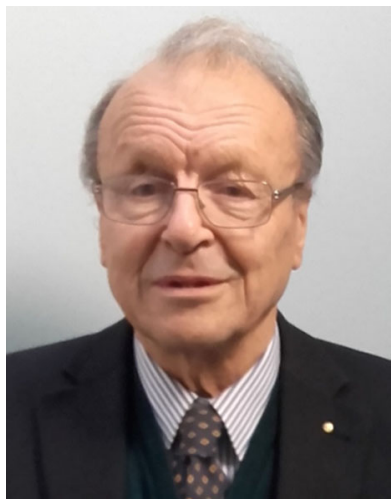

\begin{abstract}
High-temperature creep, cyclic deformation in saturation, and a number of technologically important processes are typical examples of the so-called "steady-state" deformation. These cases are usually defined in terms of the constancy of the mechanical parameters. Moreover, it is usually assumed that the deformation-induced microstructure undergoes no further changes. However, clear evidence shows that non-negligible microstructural changes continue to occur in the so-defined steady-state high-temperature creep and in cyclic saturation. It can be shown that the so-called "steady-state" deformation is actually a quasi-stationary deformation which is characterized by the initial development of a "mechanical steady state", which is followed with a delay by a "microstructural steady state." Only the latter can then be considered as a true steady state. A deeper analysis reveals a persistent slight increase of the dislocation density, with geometrically necessary dislocations in the cell walls/subgrain boundaries, causing the latter to transform gradually into sharper boundaries with higher misorientations. These findings, based on a detailed analysis of a wide range of experimental studies, are found to be almost identical for both high-temperature creep and cyclic deformation in saturation and are hence considered as characteristic of quasi-stationary deformation. The analysis clarifies, as a by-product, specific effects which arise from the increasing heterogeneity of the dislocation pattern (patterning). Thus, a marked decrease of the arrangement factor "alpha" in the Taylor flow stress is noted, as patterning proceeds, in agreement with predictions of the so-called composite model. Since this effect is compensated partially by the increase of the dislocation density, the flow stress remains rather insensitive to subtle microstructural changes. Based on these facts, the need for revision of current flow-stress formulations in future dislocation modeling is emphasized.
\end{abstract}

https://doi.org/10.1007/s11661-019-05618-x

(c) The Author(s) 2020

HAËL MUGHRABI is with the Department of Materials Science and Engineering, Lehrstuhl Werkstoffwissenschaften I, University of Erlangen-Nürnberg, Martensstrasse 5, 91058 Erlangen, Germany. Contact e-mail: hael.mughrabi@fau.de

Haël Mughrabi has received his Ph.D. in physics from Stuttgart University. Germany in 1970. Until 1983, he was a senior researcher at the Max Planck Institute of Metal Research in Stuttgart, where he performed research in the fields of crystal defects and crystal plasticity. In 1978/79, he was a Visiting Professor at Cornell University. He was appointed as professor of Materials Science and Engineering and Director of the Institute of General Materials Properties at the University of Erlangen-Nürnberg in 1984, where he then held positions as Department Head and Dean of the School of Engineering. Since his retirement as a Professor Emeritus in 2002, he has remained active in different ways. $\mathrm{He}$ has published more than 300 papers/book chapters in the fields of crystal plasticity, materials characterization, internal stresses, metal fatigue, and mechanical properties of high-temperature and ultrafine-grained materials. $\mathrm{He}$ has been editor/co-editor of several books/journals and conference proceedings. His work was acknowledged in ISI Highly Cited Researchers. He has been a frequent plenary/keynote speaker. He is a member of several professional societies. He was honored by an Honorary Symposium at the TMS Meeting in 2008, elected to Honorary Membership of the German Materials Society (Deutsche Gesellschaft für Materialkunde, DGM) and received several national/ international awards, including the highest award of DGM, the Heyn-Denkmünze, and an honorary doctoral degree from the Ruhr-University in Bochum.

Manuscript submitted August 6, 2019

Article published online February 3, 2020 


\section{INTRODUCTION}

THE so-called "steady-state" deformation is frequently encountered under a variety of circumstances in different areas of science and engineering. Quite generally, one speaks of a "steady-state" process, when the variables that define the behavior are unchanging in time. There exists a wide range of different "steadystate" processes of scientific and/or technological importance, such as

- Different types of deformation processing, e.g., rolling, extrusion, drawing, ${ }^{[1,2]}$

- Severe plastic deformation (SPD) such as ECAP (Equal Channel Angular Pressing) or HPT (High-Pressure Torsion), ${ }^{[3,4]}$

- Geological events, such as motion of tectonic plates, earth quakes, ${ }^{[5,6]}$

- Cosmology, e.g., expansion of the universe, ${ }^{[7]}$ and so on.

Modeling of the so-called "steady-state" processes is popular and mathematically convenient, because the equations simplify considerably, when the differential changes of the behavior reduce to zero. Here, our interest is focussed on a materials science topic of fundamental importance in crystal plasticity, namely on the so-called "steady-state" deformation, as evidenced in

- High-temperature creep, and in

- Cyclic deformation in saturation.

In these two cases, "steady-state" deformation is generally defined in terms of the constancy of the mechanical parameters which define the deformation, e.g., the stress and the strain rate. However, it must also be kept in mind that crystal plasticity is always closely related to variations of the dislocation microstructure. This raises the question: "Is the microstructure constant in so-called "steady-state" deformation in the two cases under consideration?" The main objective of the present work is to discuss and to clarify this question, based on experimental data and on current concepts of crystal plasticity. A strong motivation for this approach lies in the increasing evidence that, in the so-called "steady-state" deformation, small but nonetheless non-negligible microstructural changes occur, as was documented earlier. ${ }^{[8,9]}$ This important aspect and its implications will be discussed in detail subsequently. It follows that, strictly speaking, there is no true steady state, defined in terms of constancy of both stress (deformation strength) and microstructure. For this reason, it is more appropriate to speak of a "quasi-stationary deformation," as will be detailed subsequently.

\section{CUSTOMARY DEFINITIONS OF "STEADY STATE" IN UNIDIRECTIONAL DEFORMATION, HIGH-TEMPERATURE CREEP AND CYCLIC DEFORMATION}

Unidirectional "steady-state" deformation: In this case, a "steady-state" situation can be obtained, if the stress-strain curve approaches a horizontal limit at a certain stress $\sigma$, as shown schematically in
Figure $1 .^{[10]}$ Then, "steady state" is defined as stress $\sigma=$ const.

High-temperature creep ${ }^{[10]}$ : In this case, "steady state" is obtained typically in the secondary creep stage, when a linear relation between strain $\varepsilon$ and time $t$ is observed, compare Figure 2(a). Thus, steady state is defined as strain rate $\dot{\varepsilon}=$ const., as shown in Figure 2(b).

Cyclic deformation ${ }^{[11-13]}$ :

(a) Stress control: In this case, "steady state" is obtained after cyclic hardening or softening, when the plastic strain amplitude, i.e., half the plastic strain range $\frac{\Delta \varepsilon_{\mathrm{pl}}}{2}$, approaches a constant value.

(b) Strain control: Steady state is obtained, when the stress amplitude (half the stress range, i.e., $\frac{\Delta \sigma}{2}$ after cyclic hardening (or softening) at a given plastic strain range $\Delta \varepsilon_{\mathrm{pl}, \mathrm{i}}(i=1,2,3, \ldots)$ approaches a constant value (i.e., $\frac{\Delta \sigma}{2}=$ const. $=$ saturation stress).

Figure 3 illustrates cyclic deformation at constant plastic strain amplitude, i.e., $\frac{\Delta \varepsilon_{\mathrm{pl}}}{2}=$ const. Figure 3(a) shows schematically hysteresis loops, with cyclic hardening at constant plastic strain amplitude until a stable hysteresis loop develops in saturation. Cyclic hardening curves, with different constant cyclic stress amplitudes in saturation, are shown in Figure 3(b) in a plot of stress amplitude $\frac{\Delta \sigma}{2}$ vs number of cycles $N$ (or the cumulative plastic strain $\varepsilon_{\mathrm{pl}, \mathrm{cum}}=2 N \cdot \Delta \varepsilon_{\mathrm{pl}}$, for different plastic strain ranges $\Delta \varepsilon_{\mathrm{pl,i}}(i=1,2,3)$.

The dependence of the cyclic saturation stress amplitude $\left(\frac{\Delta \sigma}{2}\right)_{\mathrm{s}}$ on the plastic strain amplitude $\frac{\Delta \varepsilon_{\mathrm{pl}}}{2}$, namely the so-called cyclic stress-strain curve (cssc), is of fundamental importance in basic formulations of cyclic

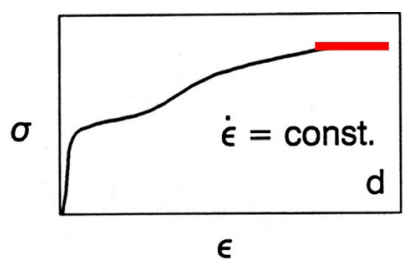

Fig. 1-Steady state in monotonic unidirectional deformation, defined as $\sigma=$ const. Adapted with permission from Ref. [10].

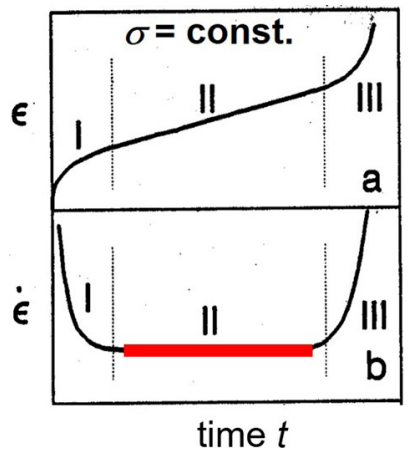

Fig. 2-Steady state in high-temperature creep, defined as $\dot{\varepsilon}=$ const. (a) Strain $\varepsilon$ vs time $t$. (b) Strain rate $\dot{\varepsilon}$ vs time $t$. Adapted with permission from Ref. [10]. 


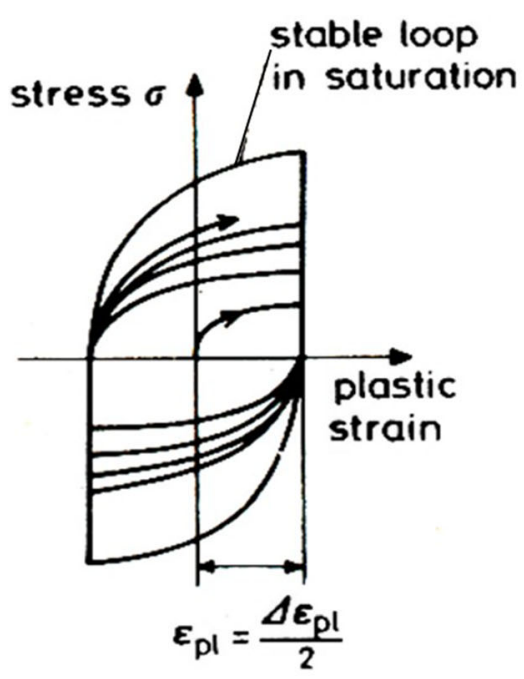

(a)

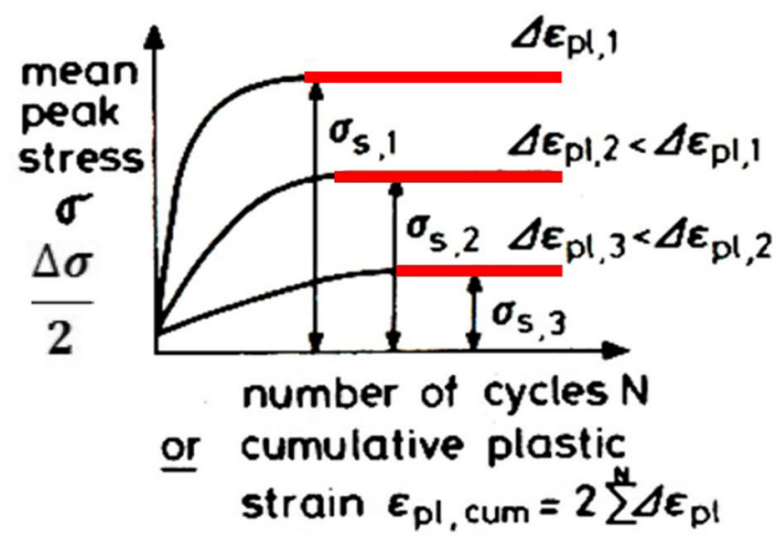

(b)

Fig. 3-Cyclic deformation. (a) Plot of cyclic stress amplitude $\sigma=\frac{\Delta \sigma}{2}$ against the plastic strain $\varepsilon_{\mathrm{pl}}$ (hysteresis loop), showing cyclic hardening until a stable hysteresis loop is attained in saturation. (b) Cyclic hardening curves: cyclic stress amplitude $\frac{\Delta \sigma}{2}$ for different plastic strain amplitudes $\frac{\Delta \varepsilon_{\mathrm{pl}}}{2}$, vs number of cycles $N$ or cumulative plastic strain $\varepsilon_{\mathrm{pl}, \text { cum }}$ until attainment of cyclic saturation stress amplitude $\left(\frac{\Delta \sigma}{2}\right)_{\mathrm{s}}$.

stress-strain and also of fatigue life laws. ${ }^{[11-13]}$ In this work, cyclic deformation in the present context will be discussed in Section VII. There, the discussion will be confined to experimental data from strain-controlled cyclic deformation tests, as shown in Figure 3.

\section{DISTINCTION BETWEEN MECHANICAL "STEADY-STATE" DEFORMATION AND MICROSTRUCTURAL "STEADY-STATE" DEFORMATION: THE CONCEPT OF "QUASI-STATIONARY DEFORMATION"}

In the following, compelling evidence will be presented showing that, during high-temperature creep and also during cyclic deformation in saturation, mild but substantial microstructural changes continue to occur persistently after the so-called "steady state," defined as described in Section II, has been achieved. Thus, the dislocation density continues to increase mildly, while the dislocation pattern becomes more heterogeneous (cell formation). These microstructural changes cease only after substantial further deformation, when finally a state of constant microstructure is attained. Thus, "steady state" in a microstructural sense lags behind "steady state" in a mechanical sense.

It is therefore expedient to distinguish between "mechanical steady-state" and "microstructural steady-state" deformations and to emphasize that, in a general sense, it is more appropriate to speak of a "quasi-stationary deformation," compare also References $9,14,15$ as will be detailed subsequently. In the following, "steady state" will not be written in inverted commas any longer.

\section{CRITERIA FOR ONGOING CHANGES IN DISLOCATION DENSITY AND ARRANGEMENT IN MECHANICAL STEADY-STATE DEFORMATION}

\section{A. Microstructural Characterization}

The analysis of microstructural changes in mechanical steady state will be based on a wide range of published earlier experimental data, most of which have not been analyzed comprehensively in similar fashion before. Essentially, the data refer to experimental documentation of mechanical properties, accompanied by measurements of electrical resistivity, magnetic properties, X-ray diffraction, and direct observations by TEM (transmission electron microscopy). These data provide information on

(a) dislocation cell/subgrain size $d$

(b) spacings $s$ between dislocations in networks

(c) dislocation density $\rho$

(d) lattice misorientations $\theta$, indicative of geometrically necessary dislocations (GNDs)

(e) dislocation arrangement (heterogeneity, patterning).

As will be discussed in Section IV-B, characteristic features of quasi-stationary deformation are that, after mechanical steady state has been attained, a small but non-negligible persistent increase of the dislocation density $\rho$ is noted, stemming, for example, from a continuing decrease of the spacings $s$ (mesh size) in the dislocation networks, and also from increases of the density of geometrically necessary dislocations (GNDs) in the dislocation cell walls/subboundaries, as evidenced from increasing misorientations across the cell walls/subboundaries, compare References 8, 9. These findings 
show that the dislocation density continues to increase in steady state and thus contradicts the current general opinion that the dislocation density is constant in steady state. Very recently, and in a somewhat different context, Huang arrived at the same conclusion. ${ }^{[16]}$

Another important feature of deformation-induced dislocation distributions is that dislocations are not distributed randomly but tend to cluster, forming dislocation wall and cell structures. It is important to clarify whether and how this phenomenon of the so-called dislocation patterning, compare Kubin, ${ }^{[17]}$ affects the constitutive equations of plasticity.

\section{B. Assessment in Relation to Taylor Flow-Stress Law}

The microstructural data will be related to the (shear) flow stress $\tau$, as described by the Taylor flow-stress $\operatorname{law}^{[18]}$ :

$$
\tau=\alpha G b \sqrt{ } \rho,
$$

where $G$ is the shear modulus, $b$ the modulus of the Burgers vector, and $\alpha$ a geometrical factor that takes into account the arrangement of the dislocations. Thus, the $\alpha$-factor should, for example, provide evidence of dislocation patterning. Usually, a value of $\alpha \approx 0.35$ to 0.4 is used, as estimated for dislocation intersection, i.e., forest cutting, first by Saada ${ }^{[19]}$ and later by Schoeck and Frydman. ${ }^{[20]}$ Variations of the $\alpha$-factor and changes of the dislocation density during the so-called steady-state deformation are normally not considered. ${ }^{[21-23]}$ In fact, one finds in the literature statements like "paradoxically, realistic strain hardening properties in uniaxial deformation are obtained without accounting for dislocation patterning, $[21]$ or that there exists "a relative insensitivity of the dislocation strengthening relation to the arrangement of the microstructure." ${ }^{[23]}$ However, in the present work, evidence will be provided, showing that as the dislocation density continues to increase mildly during mechanical steady-state deformation, the $\alpha$-factor varies and can in fact decrease by about 20 pct. This conclusion was first drawn qualitatively about 45 years ago from a study on cyclically deformed $\alpha$-iron single crystals in cyclic saturation $^{[24]}$ and has been substantiated since, compare References 8, 9, 25. In the next Section, it will be shown in a simple dislocation model that the $\alpha$-factor is expected to decrease as the dislocation distribution becomes more heterogeneous in the process of clustering of dislocations and/or the development of a cell structure.

\section{CONSIDERATION OF THE EFFECTS OF HETEROGENEITY OF DISLOCATION MICROSTRUCTURES IN DEFORMED MATERIALS ON THE FLOW STRESS}

\section{A. General Features}

Examples of dislocation microstructures in different deformed metals and alloys are shown in Figure 4 for

\section{Tensile deformation}
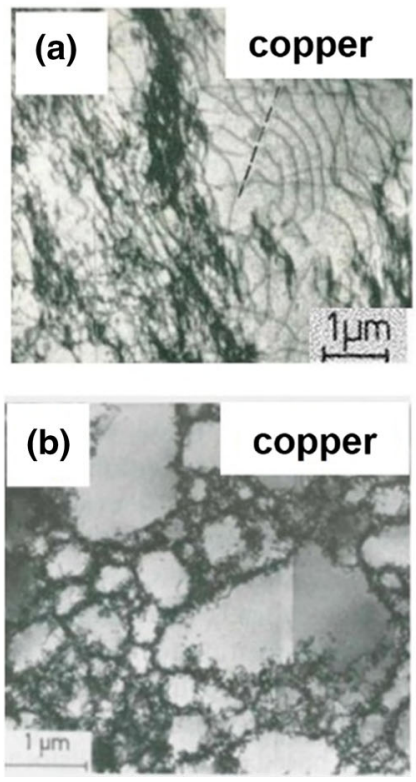

Cyclic deformation
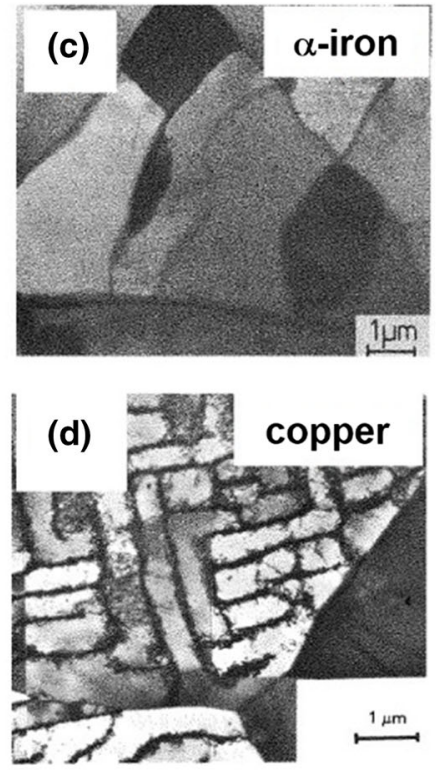

High-temp. creep deformation
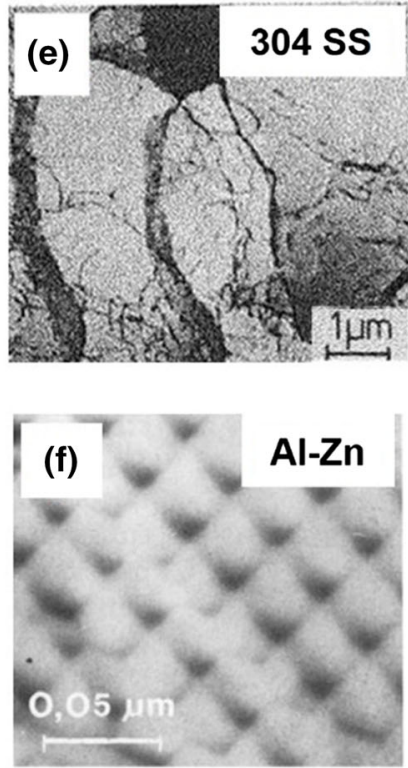

Fig. 4-Examples of dislocation arrangements in different materials after tensile, cyclic, and high-temperature creep deformations, to illustrate the large variety and heterogeneity of deformation-induced dislocation patterns. $(a)$ Tensile-deformed copper single crystal, primary glide plane, single slip, reprinted with permission from Ref. [26]. (b) Tensile-deformed copper single crystal, [001]-orientation, multiple slip, reprinted with permission from Ref. [27]. (c) Cyclically deformed $\alpha$-iron single crystal of single slip orientation, see also Ref. [28]. (d) Cyclically deformed copper polycrystal, "labyrinth" structure, reprinted with permission from Ref. [29]. (e) Creep-deformed stainless steel AISI 304, reprinted with permission from Ref. [30]. (f) Creep-deformed Al-Zn alloy, reprinted with permission from Ref. [31]. 
unidirectional deformation $^{[26,27]}$ (Figures 4(a) and (b)), cyclic deformation ${ }^{[9,28,29]}$ (Figures 4(c) and (d)), and high-temperature creep $^{[30,31]}$ (Figures 4(e) and (f)). It is obvious that these dislocation microstructures are rather complex and differ considerably. Nonetheless, they have one thing in common. In all cases, the distribution of the dislocations is rather heterogeneous, with areas of low and high local dislocation densities, respectively.

\section{B. Description in Terms of the Two-Component Composite Model}

It is desirable to describe at least semi-quantitatively the properties and the flow stresses of deformed materials containing different heterogeneous dislocation distributions. In the simplest possible procedure, the flow stress for a homogeneous dislocation distribution with a total mean dislocation density $\rho$ is described in terms of the Taylor flow stress $\tau_{\text {Taylor }}$ and denoted as $\tau_{\text {hom }}$ with an arrangement factor $\alpha_{\text {hom }}$ :

$$
\begin{gathered}
\tau_{\text {Taylor }}=\alpha G b \sqrt{\rho}=\tau_{\text {hom }} \\
\tau_{\text {hom }}=\alpha_{\text {hom }} G b \sqrt{\rho} .
\end{gathered}
$$

Usually, the value of $\alpha_{\text {hom }}$ is considered to lie in the range $\alpha_{\text {hom }} \approx 0.35$ to 0.4 which is characteristic of dislocation cutting, as stated earlier.

In the case of a heterogeneous dislocation distribution, the simplest approach is to describe the flow stress $\tau_{\text {het }}$ in terms of the two-component composite model $^{[25,32,33]}$ which considers only dislocation cell wall regions of high local dislocation density $\rho_{\mathrm{w}}$ with a volume fraction $f_{\mathrm{w}}$ and cell interior regions of lower local dislocation density $\rho_{\mathrm{c}}$ with a volume fraction $f_{\mathrm{c}}$. For simplicity, the $\alpha$-factor is taken to be the same in the cell walls and in the cell interiors. Then, the flow stress $\tau_{\text {het }}$ can be written in terms of a rule of mixtures with the weighted contributions of the dislocation cell walls and cell interiors:

$$
\tau_{\text {het }}=f_{\mathrm{w}} \alpha G b \sqrt{\rho_{\mathrm{w}}}+f_{\mathrm{c}} \alpha G b \sqrt{\rho_{\mathrm{c}}}
$$

When the terms are lumped together, the flow stress $\tau_{\text {het }}$ can be expressed as

$$
\tau_{\text {het }}=\alpha_{\text {het }} G b \sqrt{\rho},
$$

with an arrangement factor $\alpha_{\text {het }}$. As shown earlier, ${ }^{[33]}$ it is easy to show that, in general, $\alpha_{\text {het }}<\alpha_{\text {hom }}$, and that the arrangement factors $\alpha_{\text {hom }}$ and $\alpha_{\text {het }}$ are related in a simple one-dimensional model in good approximation as

$$
\alpha_{\mathrm{het}} \approx 2 \alpha_{\mathrm{hom}} \sqrt{f_{w} f_{c}}
$$

In this model, one finds $\alpha_{\text {het }}<\alpha_{\text {hom }}$ in all cases, except in the case of a homogeneous distribution, characterized by $f_{\mathrm{c}}=f_{\mathrm{w}}$, where one finds $\alpha_{\text {het }}=\alpha_{\mathrm{hom}}$, as expected. In this limit, there is no distinction between cell walls and cell interiors. Thus, in the model described earlier, the terms $f_{\mathrm{c}}$ and $f_{\mathrm{w}}$ are interchangeable. ${ }^{[9,33]}$ With increasing heterogeneity, the volume fraction $f_{\mathrm{c}}$ of cell interiors decreases with increasing deformation to typical values in the range of, say 0.3 to 0.1 . Inserting these values into Eq. [6], one obtains, with $\alpha_{\text {hom }} \approx 0.4$, values of

$0.24<\alpha_{\text {het }}<0.36$ in the range of $0.1<f_{\mathrm{c}}<0.3$.

It follows from the cross check that, at the same time, $f_{\mathrm{w}}$ increases, in agreement with the experimental finding that the volume fraction of the walls increases with increasing deformation. ${ }^{[27]}$ It is pointed out that, in the original work ${ }^{[33]}$ and in an earlier publication, ${ }^{[9]}$ the range of values of the volume fractions were formulated in terms of $0.1<f_{\mathrm{w}}<0.3$ instead of $0.1<f_{\mathrm{c}}<0.3$, and the same basic conclusions regarding $\alpha_{\text {het }}$ were drawn. However, strictly speaking, this formulation would have implied incorrectly that the volume fraction of walls would decrease with increasing deformation, in disagreement with experiment. ${ }^{[27]}$

In summary, it is predicted that the arrangement factor $\alpha_{\text {het }}$ is expected to decrease with increasing heterogeneity of the dislocation distribution in the course of increasing deformation, from approximately 0.36 to about 0.24 , i.e., by about 30 pct. In the following sections, based on the assessment of substantial experimental evidence. this rather large effect will be substantiated and verified.

\section{Comparison of the Effects of Heterogeneity and of the Basinski Flow-Stress Correction on the Arrangement Factor $\alpha$ in the Taylor Flow-Stress Law}

Basinski modified the Taylor flow-stress equation, based on the argument that, when a dislocation bows out between two obstacles, the spacing between the obstacles, i.e., $1 / \sqrt{ } \rho$, should appear in the flow-stress equation as an outer cut-off radius. ${ }^{[34]}$ Thus, Basinski proposed the following corrected flow-stress law:

$$
\tau_{\mathrm{Bas}}=\alpha G b \sqrt{\rho} \ln 1 / \sqrt{\rho} .
$$

When the logarithmic term is lumped into the $\alpha$-factor, the effect of the Basinski correction corresponds qualitatively also to a decrease of the $\alpha$-factor in the Taylor flow-stress law, as in the previously discussed case of increasing heterogeneity. However, as elaborated by Sauzay and Kubin, ${ }^{[23]}$ the Basinski correction corresponds (only) to a modest decrease of the $\alpha$-factor, namely 11 pct per decade in dislocation density. Thus, for example, assuming a value $\alpha=0.35$ for a dislocation density of $10^{13} \mathrm{~m}^{-2}$, a value $\alpha=0.31$ would follow, if the dislocation density increased by one order of magnitude to $10^{14} \mathrm{~m}^{-2}$. In other words, a tenfold increase in dislocation density would cause the $\alpha$-factor to decrease by less than only 12 pct.

By comparison with the effect of heterogeneity in the composite model, an important conclusion follows: Even without any increase of dislocation density (!), the effect of increasing heterogeneity during deformation on the $\alpha$-factor is significantly larger than the effect of the Basinski correction, and can amount up to about 
20 to 30 pct. To the author's knowledge, this rather strong effect of heterogeneity on the "effective" value of the arrangement factor $\alpha$ (for a given constant dislocation density!) has generally not been considered in the past or in more recent comprehensive discrete dislocation dynamics modeling (DDD) simulations, compare, for example, the work of Kubin and co-workers. ${ }^{21,22]}$ The present statements will be substantiated amply in the following by a large body of experimental evidence.

\section{STEADY-STATE HIGH-TEMPERATURE CREEP DEFORMATION}

\section{A. The Assumption That the Dislocation Density Remains Constant}

Under the so-called steady-state conditions, it is assumed that the flow stress $\tau$ remains constant, i.e.,

$$
\tau=\alpha G b \sqrt{ } \rho=\text { const. }
$$

This implies that the dislocation density $\rho$ does not change, i.e., that the dislocation production and annihilation rates are equal and compensate each other. At the same time, the $\alpha$-factor is considered to remain constant during deformation. In the present work, these assumptions are questioned in the light of experimental observations. Further details follow in the next section by considering the assumptions that are made in order to derive a constant steady-state creep rate.

\section{B. Assumptions Underlying the Derivation of a Steady-State Creep Rate: The Recovery Creep Model $^{[35]}$ Revisited}

As stated earlier and as is well known, the condition for steady-state creep is strain rate $\dot{\varepsilon}=$ const. In the context of the present work, it is important to discuss critically the underlying assumptions that lead to this definition of steady-state creep. For this purpose, the derivation of the well-known recovery creep model ${ }^{[35]}$ is recalled.

Quite generally, the shear flow stress can be expressed according to Seeger ${ }^{[36]}$ as follows:

$$
\tau=\tau_{\mathrm{G}}+\tau^{*}(\dot{\varepsilon}, T)
$$

where $\tau_{G}$ represents the so-called athermal stress that depends on temperature only through the temperature dependence of the shear modulus $G$ and is given by the Taylor flow-stress law, as introduced in Eq. [1]:

$$
\tau_{\mathrm{G}}=\alpha G b \sqrt{\rho}(\text { with } \alpha=\text { const. })
$$

On the other hand, $\tau^{*}(\dot{\varepsilon}, T)$ is the so-called effective or thermal stress that contains the dependence on temperature $T$ and strain rate $\dot{\varepsilon}$. Following Bailey and Orowan, see Cottrell, ${ }^{[35]}$ the differential change of the (axial) flow stress $\sigma$ can be written in terms of a strain-dependent hardening term $h$ and a time-dependent recovery term $r$ as follows:

$$
\begin{aligned}
& \mathrm{d} \sigma=\frac{\partial \sigma}{\partial \varepsilon} \mathrm{d} \varepsilon+\frac{\partial \sigma}{\partial t} \mathrm{~d} t \\
& \mathrm{~d} \sigma=h \cdot \mathrm{d} \varepsilon-r \cdot \mathrm{d} t
\end{aligned}
$$

Steady state is attained, when the dislocation production rate $\dot{\rho}^{+}$is exactly balanced by the dislocation annihilation rate $\dot{\rho}^{-}$, i.e.,

$$
\dot{\rho}^{+}=\dot{\rho}^{-}
$$

Then, $\mathrm{d} \sigma=0$, and one obtains from Eqs. [10] and [11] the well-known following result for the "steady-state" creep rate:

$$
\dot{\varepsilon}_{S S}=-\frac{r}{h}
$$

In the following, one major point will be to show that the assumption made in Eq. [12] and the assumption made earlier, namely that the dislocation densities (and hence the flow stress) remain constant, Eq. [7], are not exactly fulfilled in the course of deformation. In fact, it will be shown that during the quasi-stationary deformation of an initially undeformed material, after a mechanical steady state has previously been attained, a persisting increase of the dislocation density is found, implying that in violation of Eq. [12].

$$
\dot{\rho}^{+}>\dot{\rho}^{-} .
$$

It will also be shown that, at the same time, the arrangement factor $\alpha$ decreases non-negligibly during quasi-stationary deformation. These two effects are largely self-compensating, thus rendering the overall effect on the flow stress marginal. A more detailed discussion will be given in Sections VI-C and VII-C.

\section{Experimental Assessment of Microstructural Changes After Attainment of Mechanical Steady State (Microstructural Steady State is Not Attained)}

In many metals and alloys, dislocation cell/subgrain structures form in high-temperature creep. Figure 5 shows two examples of dislocation subboundaries of a creep-deformed Al-11 wt petZn alloy. ${ }^{[31]}$ In general, such subboundaries consist of networks composed of dislocations of two or more interacting slip systems. The spacings $s$ in the subboundaries can be determined from such micrographs. Here, it is of interest to note that, even during the so-called steady-state creep, after the strain rate has become constant, these cell structures continue to undergo appreciable changes. According to our earlier definitions, compare Section III, this case of mechanical steady-state creep is simply a preliminary stage in the process of quasi-stationary creep deformation. In the subsequent assessment of the microstructural changes which persist in this stage of creep deformation, the following features of the dislocation pattern should be documented carefully: changes of the cell/subgrain size $d$, changes of the dislocation spacings $s$ (mesh size), changes of the dislocation density $\rho$, and changes of the lattice misorientations $\theta$ across the cell boundaries. 

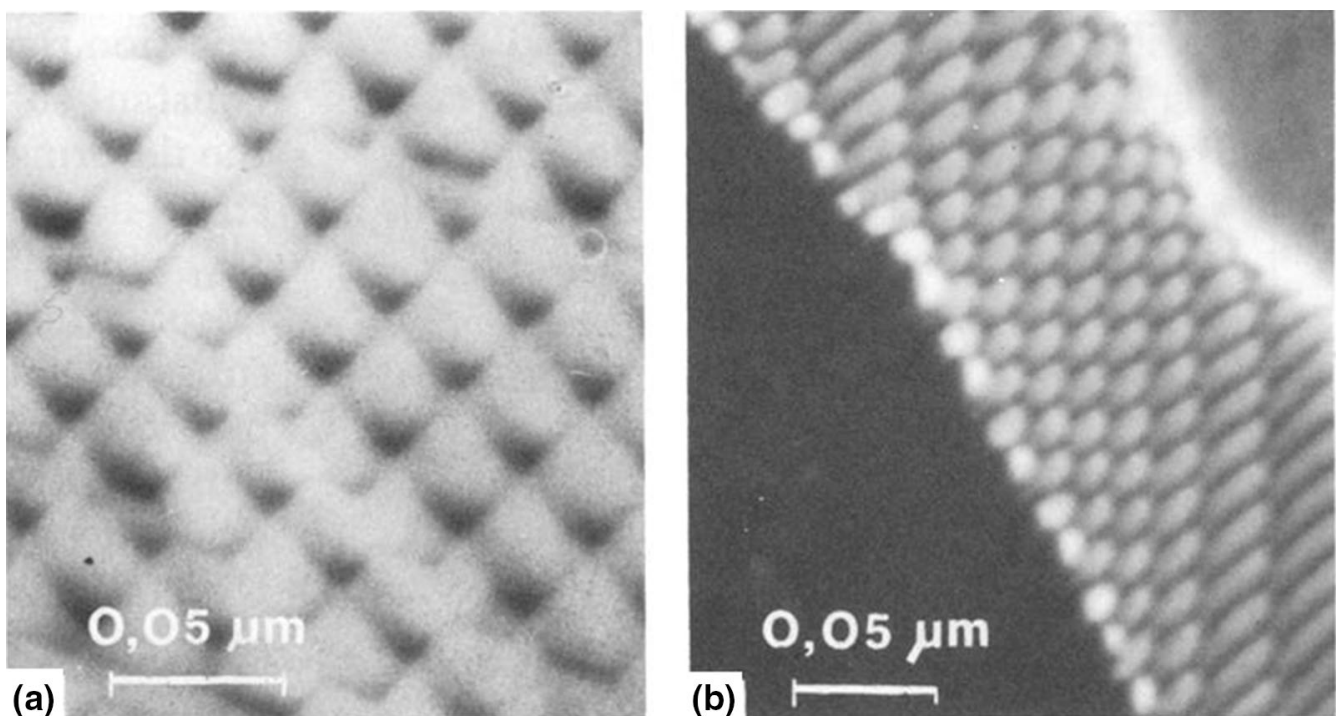

Fig. 5-Two examples of different dislocation subboundary microstructures in creep-deformed Al-11 wt pctZn alloy. Reprinted with permission from Ref. [31].

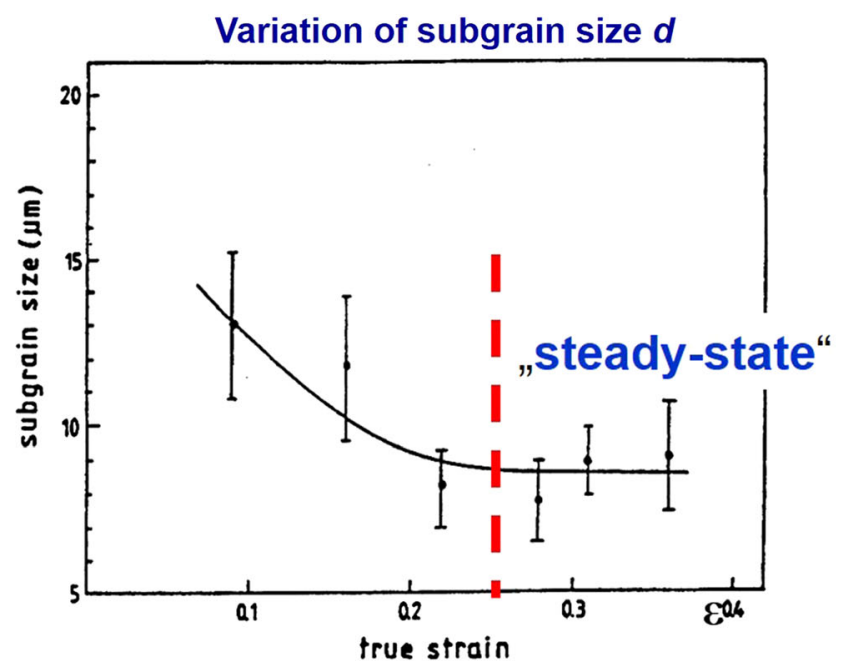

(a)

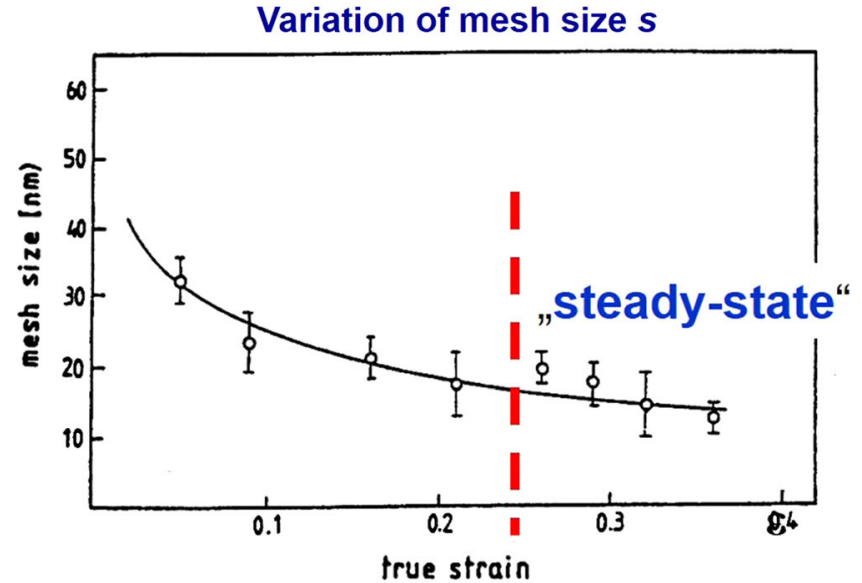

(b)

Fig. 6-Variations of the subgrain size $d$ and mesh size $s$ in creep-deformed Al-11 wt pctZn alloy. (a) Decrease of dislocation subgrain/cell sizes until attainment of steady state, i.e., $d=$ const. $(b)$ Continued decrease of dislocation spacings $s$ (mesh size) after attainment of steady state. Adapted with permission from Ref. [31].

In Figures 6(a) and (b), the variations of the subgrain size $d$ and the mesh size $s$ in creep-deformed Al-11 wt pctZn alloy ${ }^{[31]}$ are shown. Even after the so-called steady state has been attained, defined by constancy of the subgrain size $d$ beyond a strain of about 0.24 (marked by the red bold broken vertical line in the figure), the dislocation spacings $s$ (mesh size) in the networks continue to decrease. In the same work, an even stronger change after entering the steady-state regime is found for the misorientations $\theta$ across the subgrain boundaries, as shown in Figure 7.

In line with this work, Blum, ${ }^{[10]}$ in a study on creep-deformed Al-5 at. pctZn, also noted that the dislocation spacings $s$ continued to decrease after the subgrain size $d$ had become constant, as shown in Figure 8 . In addition, Blum was able to show that the $\alpha$-factor decreased systematically by about 25 pct with increasing strain $\varepsilon$, namely from 0.38 to 0.27 , as the strain increased from 0.02 to 0.32 , compare Table I. This behavior is in satisfactory semi-quantitative agreement with the prediction derived in Section V-B.

Kassner et al. ${ }^{[37,38]}$ found very similar results, as those shown in Figure 6 for creep-deformed Al-11 wt pctZn alloy, in a study of creep-deformed 304 stainless steel. These data are shown in Figure 9. In another study, Kassner and McMahon showed that, in creep-deformed 


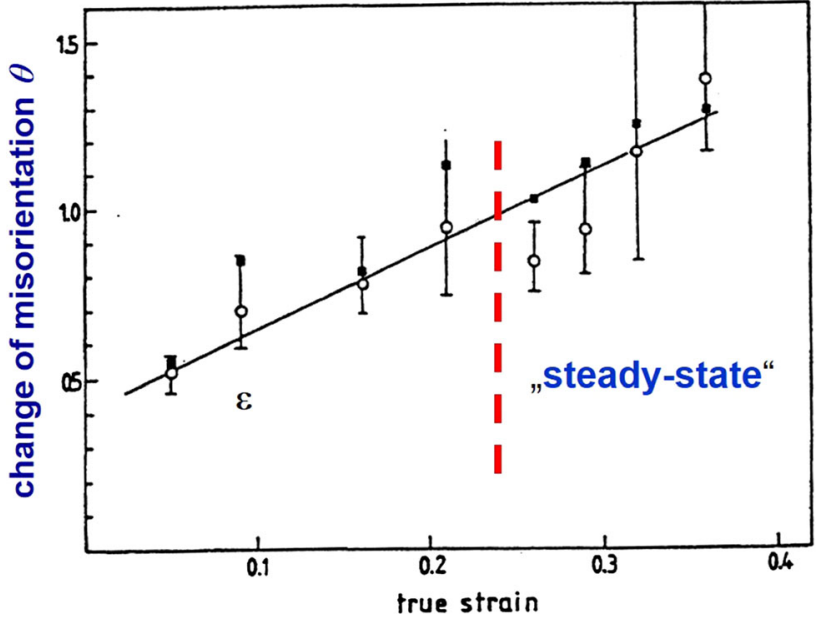

Fig. 7-Continued increase of misorientations $\theta$ across subgrain (cell) boundaries after attainment of steady state $(\dot{\varepsilon}=$ const. $d=$ const.) in creep-deformed Al-11 wt petZn alloy. Adapted with permission from Ref. [31].

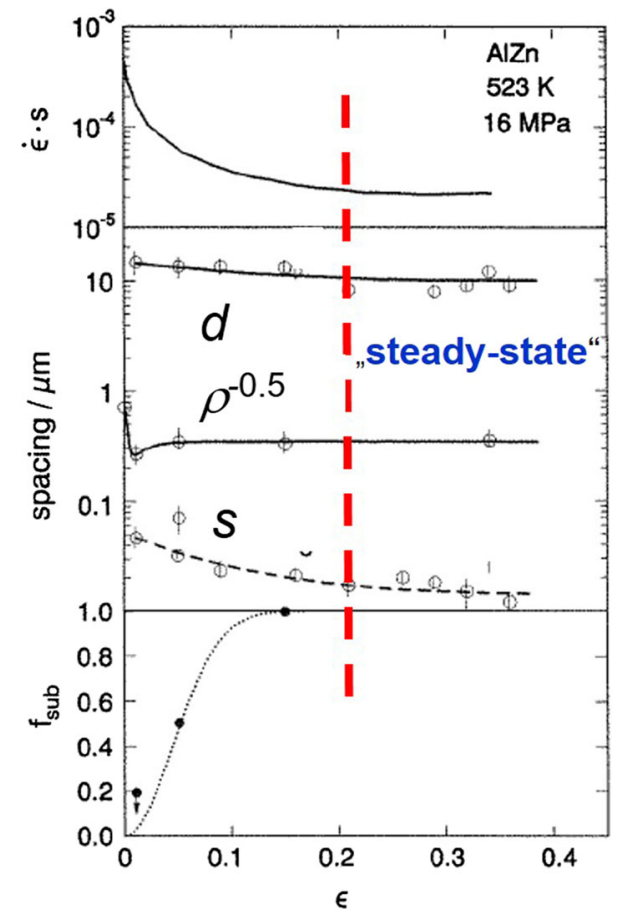

Fig. 8 - Creep deformation of $\mathrm{Al}-5$ at. pctZn alloy well into steady state (strain rate $\dot{\varepsilon}=$ const., top subfigure, and subcell size $d=$ const., medium subfigure). Note continued decrease of dislocation spacings $s$ after attainment of steady state (medium subfigure). The variations of the dislocation density $\rho$ and of the volume fraction $f_{\text {sub }}$ of subcells are also shown. Adapted with permission from Ref. [10].

aluminum, some low-angle boundaries transform into high-angle boundaries ${ }^{[39]}$ with larger misorientations with increasing strain, compare Figure 10. In summary, it is evident that in the so-called steady-state creep, after the subgrain size has become constant, the misorientations continue to increase, while at the same time the
Table I. Variation of $\alpha$-Factor with Increasing Creep Strain $\varepsilon$ in Creep-Deformed Al-5 at. pctZn ALLOY

\begin{tabular}{lc}
\hline$\varepsilon$ & $\alpha$ \\
\hline 0.02 & 0.38 \\
0.05 & 0.33 \\
0.32 & 0.27 \\
\hline
\end{tabular}

Values According to Blum ${ }^{[10]}$

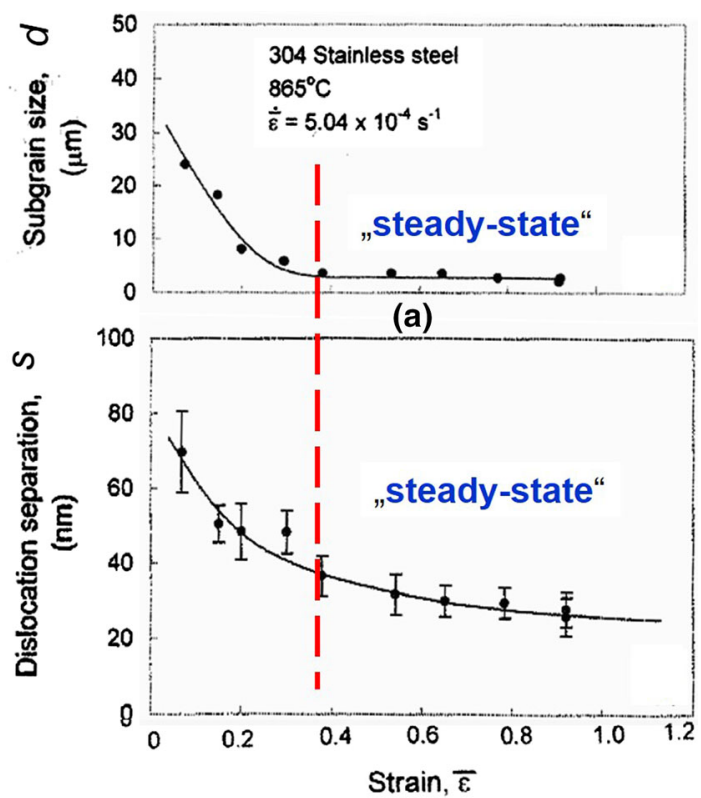

(b)

Fig. 9-Variations of the subgrain size $d$ and mesh size $s$ in creep-deformed stainless steel AISI 304..$^{[37,38]}(a)$ Decrease of dislocation subgrain sizes until attainment of steady state, i.e., $d=$ const. (b) Continued decrease of dislocation spacings $s$ after attainment of steady state. Adapted with permission from Ref. [37].

dislocation spacings $s$ decrease. The decrease of $s$ at constant cell size $d$ implies that the overall dislocation density $\rho$ has increased. Since misorientations are generally accommodated by geometrically necessary dislocations (GNDs), it is suggested that GNDs contribute appreciably to the increase of the dislocation density. In related work, Kassner and Perez-Prado ${ }^{[37]}$ substantiated the noted increase of misorientation angle and the continuing decrease of the dislocation spacings by considering other published work on different materials.

In summary, after attainment of mechanical steadystate creep deformation, defined by the constancy of the cell/subgrain size, the following microstructural changes continue persistently:

(a) the dislocation spacings $s$ (mesh size) in the cell wall networks continue to decrease

(b) the lattice misorientations $\theta$ across the subgrain/cell boundaries continue to increase, indicative of an increasing content of GNDs

(c) the overall dislocation density $\rho$, with an appreciable GND content, increases 


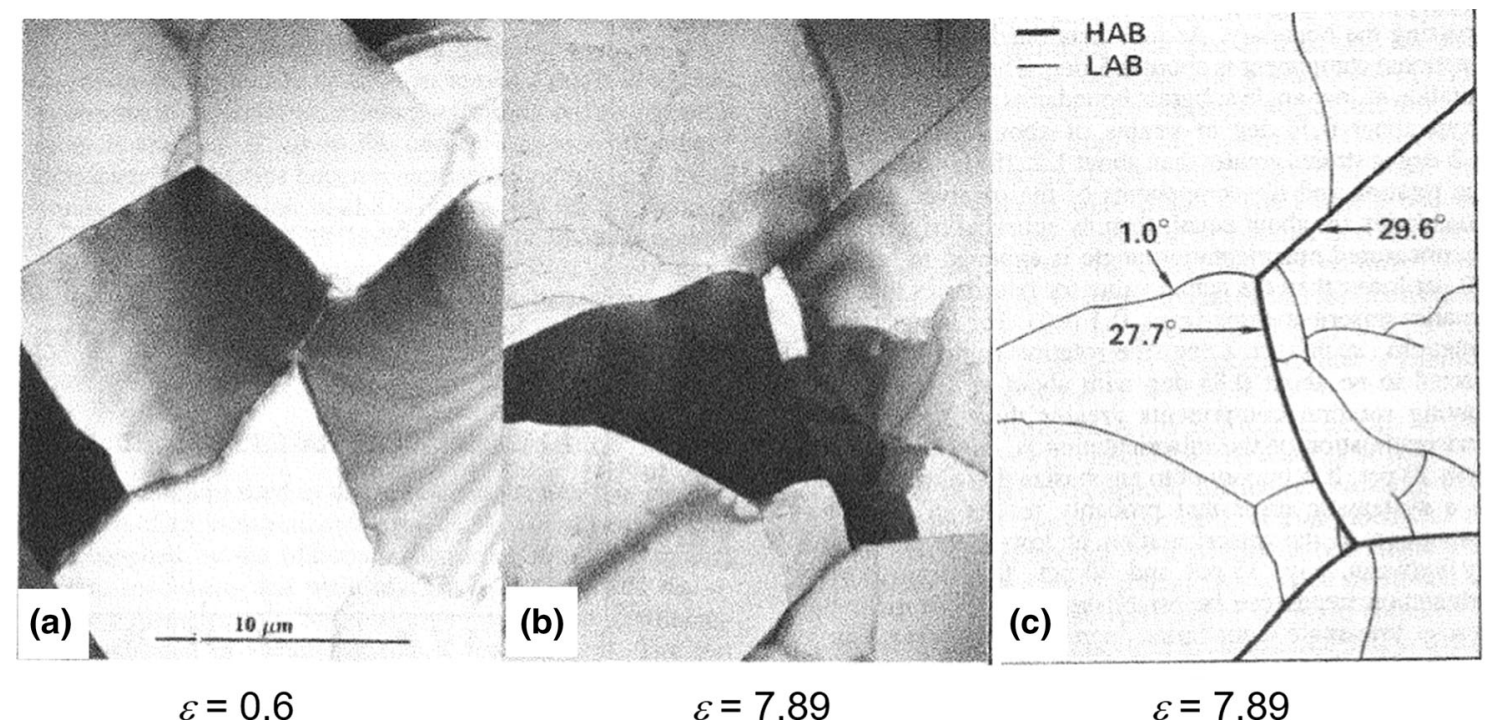

Fig. 10 - Creep-deformed aluminum. ${ }^{[39]}$ (a) Low-angle grain boundaries at $\varepsilon=0.6$. (b) Increasing fraction of high-angle grain boundaries at $\varepsilon=$ 7.89. (c) Increasing misorientations, referring to (b) at $\varepsilon=7.89$. Reprinted with permission from Ref. [39].

(d) the $\alpha$-factor decreases systematically with increasing creep strain.

Finally, it should be noted that the microstructural changes observed during quasi-stationary high-temperature creep do not come to a halt, because typical creep strains are rather small and do not exceed some 10 pct. Thus, a final constant steady-state microstructure is usually not reached. In contrast, to be shown subsequently, in cyclically deformed materials, where large cumulative plastic strains of some 100 pct are reached, the microstructure ultimately attains a true microstructural steady state.

\section{Insensitivity of the Flow Stress to Small Microstructural Changes}

The preceding discussion has shown that non-negligible microstructural changes occur at constant flow stress in quasi-stationary creep. In order to understand this behavior, the following flow-stress equation in the form introduced by Ashby, ${ }^{[40]}$ with a modification by the author, ${ }^{[41]}$ is discussed:

$$
\tau=\alpha G b \sqrt{\rho_{s}+\beta \rho_{G}}
$$

In this equation, $\rho_{\mathrm{s}}$ and $\rho_{\mathrm{G}}$ denote the densities of statistically stored and geometrically necessary dislocations, respectively. The factor $\beta$ takes into consideration that only a fraction $\beta<1$ of the geometrically necessary dislocations that act as forest dislocations enhances the flow stress. ${ }^{[41,42]}$ Based on the preceding discussion of the observed microstructural changes, it follows that the term $\rho_{\mathrm{s}}+\beta \rho_{\mathrm{G}}$ increases during deformation. However, since the $\alpha$-factor decreases at the same time, these two effects are almost self-compensating. Altogether, the increase of $\rho_{\mathrm{s}}+\beta \rho_{\mathrm{G}}$ thus has little effect on the flow stress.

\section{STEADY-STATE CYCLIC DEFORMATION IN SATURATION}

\section{A. Relation Between Steady-State Cyclic Deformation and Cyclic Slip Irreversibility}

In cyclic deformation, dislocations glide to and fro. At very small strain amplitudes and hence very small dislocation glide paths, it becomes improbable that two dislocations of opposite sign will annihilate mutually when they meet. For a particular type of dislocations, arranged in groups of $n$ dislocations, the condition that dislocations will not annihilate can be formulated for a plastic shear strain amplitude $\gamma_{\mathrm{pl}}$ and an annihilation distance $y$ in terms of a parameter $\beta$ as follows ${ }^{[42]}$ :

$$
\beta=\frac{2 \gamma_{\mathrm{pl}} y}{b n}<1
$$

This implies that as long as $\beta<1$, the same dislocations can travel to and fro reversibly without any microstructural changes, whereas for $\beta \geq 1$, annihilations will occur and slip becomes irreversible. In this latter case, steady state will be maintained through a dynamic equilibrium between generation and annihilation of dislocations. Under conditions of partly irreversible slip, a cyclic slip irreversibility $p$ can be defined as the ratio between the irreversible part $\gamma_{\mathrm{pl} \text {,irr }}$ of the shear strain amplitude and the shear strain amplitude $\gamma_{\mathrm{pl}}$ as follows:

$$
p=\frac{\gamma_{\mathrm{pl}, \text { irr }}}{\gamma_{\mathrm{pl}}}
$$

Thus, slip will be reversible for $p=0$ and increasingly irreversible for $p>0$. In the first (trivial) case, steady state is maintained without any microstructural changes, whereas in the second case, steady state obtains through a dynamic equilibrium between generation and annihilation of dislocations. 

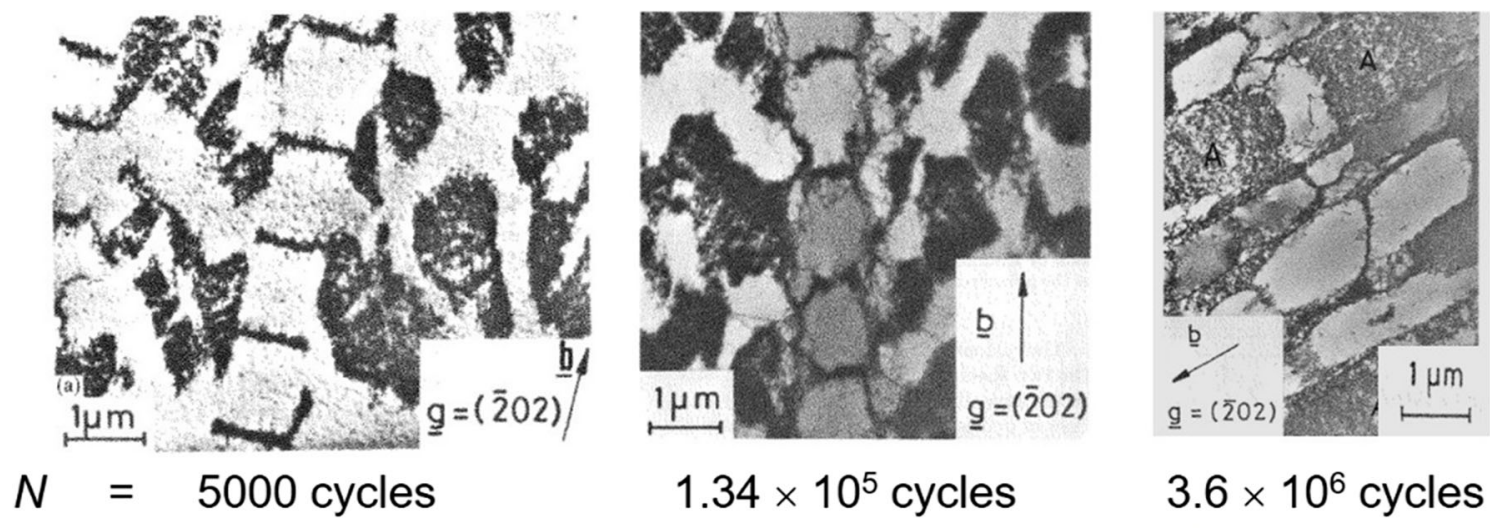

\section{increasing number of cycles}

Fig. 11-Microstructural changes in "ladder" structure (primary edge dislocation walls) of persistent slip bands (PSBs) in fatigued copper single crystals, based on unpublished work in Ref. [43]. (a) Early stage, $N=5000$ cycles. (b) Later stage, $N=1.34 \times 10^{5}$ cycles. (c) Much later stage, $N=3.6 \times 10^{6}$ cycles.

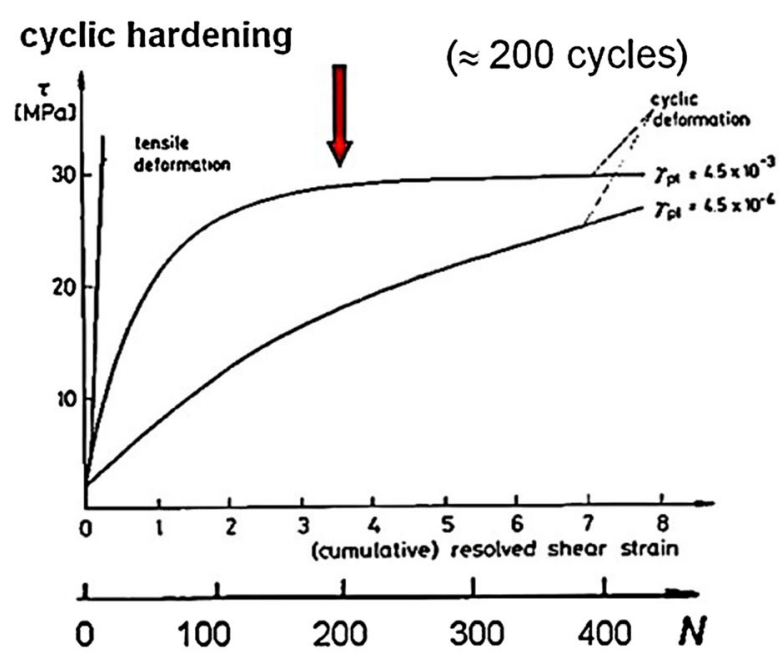

(a)

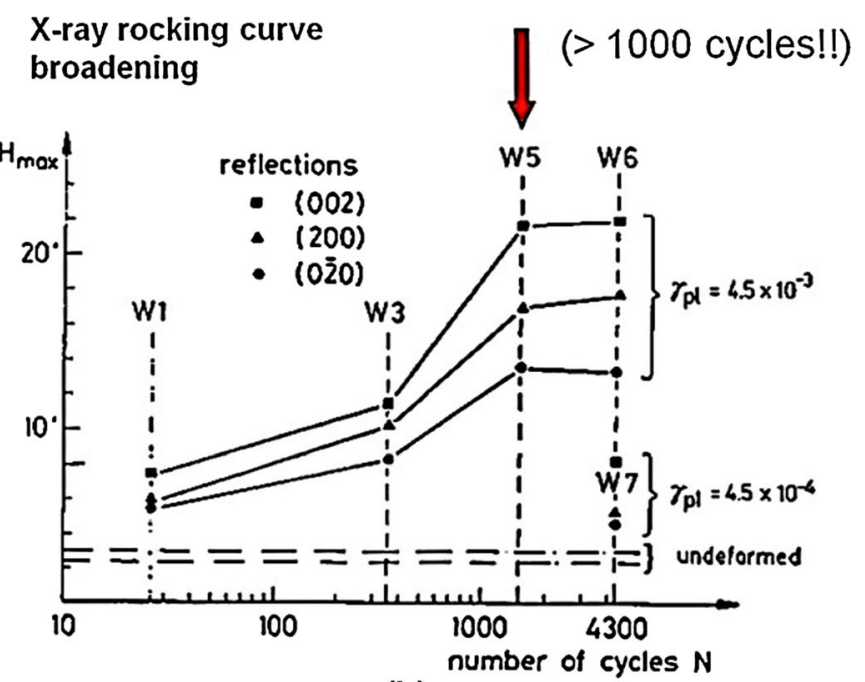

(b)

Fig. 12 - Cyclic hardening and increasing lattice misorientations in cyclically deformed copper single crystals. ${ }^{[46]}$ (a) Cyclic peak shear stress $\tau$ vs number of cycles $N$, shear strain amplitude $\gamma_{\mathrm{pl}}=4.5 \times 10^{-3}$. Saturation (indicated by vertical red arrows) occurs after ca. 200 cycles. $(b)$ Broadening of X-ray rocking curves for reflections of type $\{200\}$ as a function of number of cycles $N$. Saturation occurs after about 2000 cycles. Adapted with permission from Ref. [46].

\section{B. Experimental Assessment of Persisting}

Microstructural Changes After Attainment of Mechanical Steady State and Final Approach to a Microstructural Steady State

Figure 11 shows a sequence of TEM micrographs obtained on copper single crystals after cyclic deformation to quite different numbers of cycles. ${ }^{[43]}$ The specimens are viewed in (12 1$)$ sections along the line direction of the primary edge dislocations and perpendicular to the primary Burgers vector $\mathbf{b}$. The sequence shows, from left to right, the well-known "ladder" structure of persistent slip bands (PSBs) with primary edge dislocation walls in the early stage (number of cycles $N=5000)$, and the variations observed at a later stage $\left(N=1.34 \times 10^{5}\right.$ cycles $)$ and at a much later stage
$\left(N=3.6 \times 10^{6}\right.$ cycles). The very high number of cycles in the latter case could only be obtained by performing the cyclic deformation in vacuum, whereby fatigue failure is delayed by about a factor $10{ }^{[43]}$ In this sequence of micrographs, there is a very slight increase of the cyclic stress amplitude, resulting from a weak "secondary" cyclic hardening. ${ }^{[44]}$ The main purpose is to illustrate the nature of the very slow specific microstructural changes that occur during prolonged cycling at almost constant stress amplitude. In early saturation (number of cycles $N=5000$ ), no dislocations are located along the interface between the PSB ladder structure and the adjacent so-called matrix (vein) structure, compare References 43, 45. Then, after $N=$ $1.34 \times 10^{5}$ cycles, the PSB-matrix interface has become 


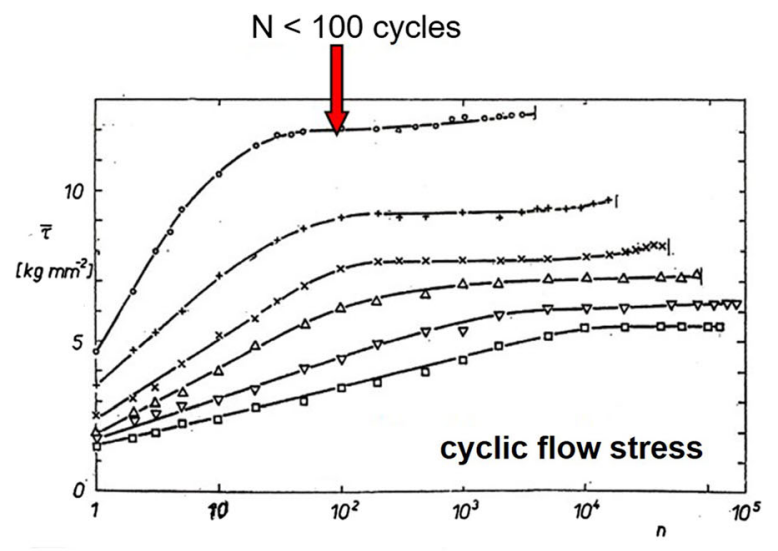

(a)

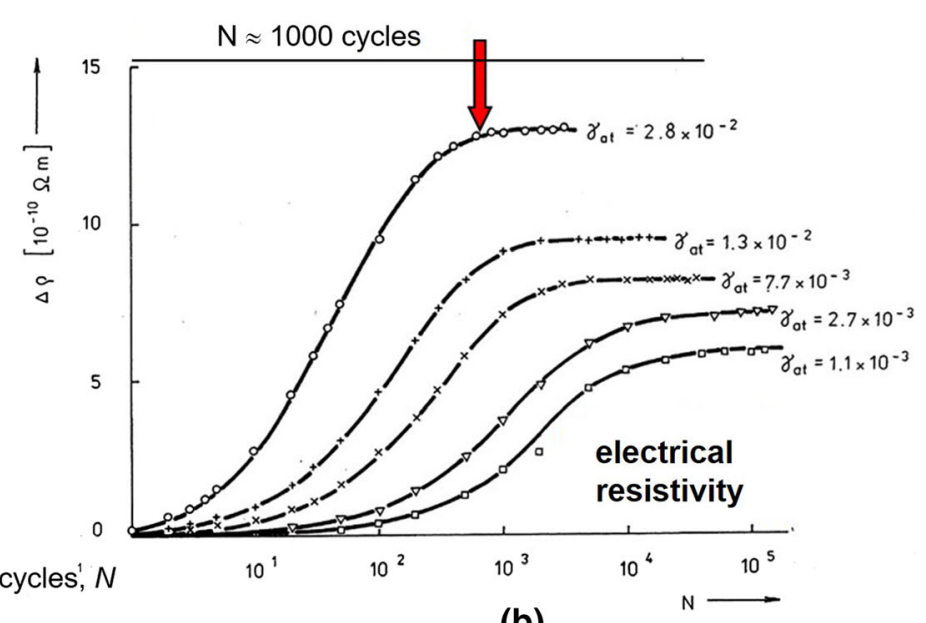

(b)

Fig. 13-Cyclic deformation in torsion of thin copper wires at $77 \mathrm{~K}^{[47]}$ With permission of Academia, Prague. (a) Shear stress $\tau$ vs number of cycles $N$. (b) Corresponding changes of the electrical resistivity $\Delta \rho_{\mathrm{el}}$ as a function of $N$. Adapted with permission from Ref. [47].

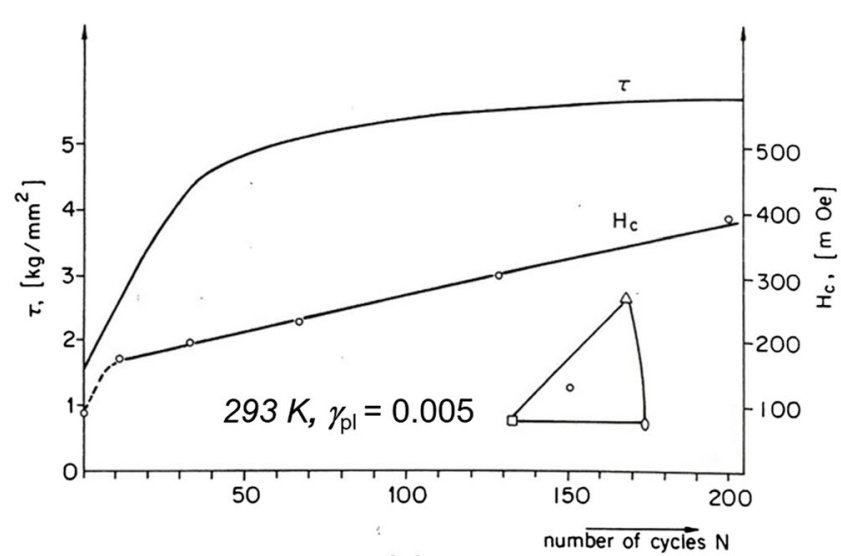

(a)

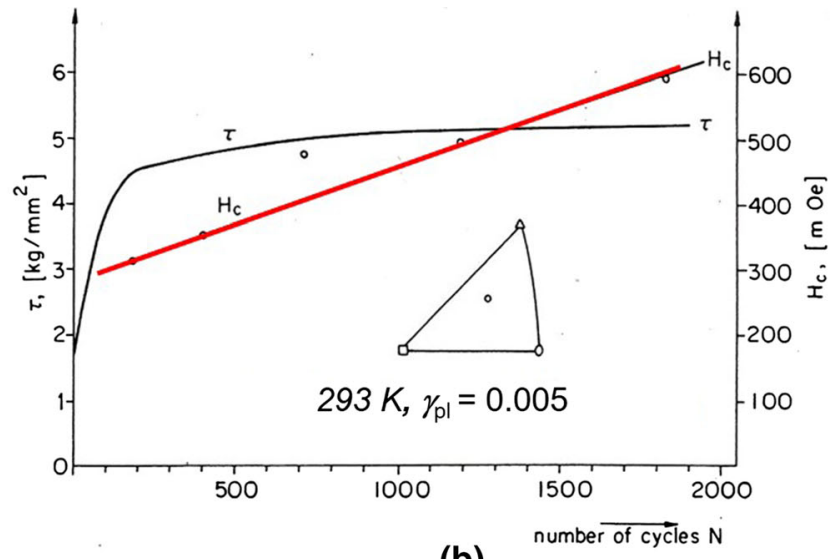

(b)

Fig. 14 Cyclic hardening and increase of coercive force $H_{\mathrm{c}}$ in cyclically deformed nickel single crystals at room temperature. (a) Up to 200 cycles. (b) Up to 2000 cycles. Note that, in the original thesis: units of coercive force $H_{\mathrm{c}}$ are in mOe, and the units of the stress are in $\mathrm{kg} / \mathrm{mm}{ }^{2}$. Adapted with permission from Ref. [48].

wiggly and is decorated with secondary dislocations, ${ }^{[43]}$ and a kind of cell structure has developed inside the PSBs. The varying background contrast indicates noticeable misorientations with respect to the matrix structure. Finally, after even larger numbers of cycles $(N$ $=3.6 \times 10^{6}$ cycles), the regular dislocation walls have been completely replaced by closed cell structures, elongated along the direction of the Burgers vector, with marked misorientations. In the present context, it is important to note that the microstructural changes observed, namely an increase of (secondary) dislocation density, including GNDs (inferred from the misorientations) and the actual misorientations develop very slowly at almost constant stress amplitude.

These findings will be addressed in more detail in the subsequent Figures 12, 13, 14, and 15, which illustrate different types of evolutions of the dislocation microstructure in real so-called steady-state cyclic deformation. Referring to the work of Wilkens et al., ${ }^{[46]}$ Figure 12(a) shows on the left two cyclic hardening curves (cyclic peak shear stress $\tau$ vs number of cycles $N$ ). Referring to the curve for the larger plastic shear strain amplitude $\gamma_{\mathrm{pl}}=4.5 \times 10^{-3}$ (saturation is indicated by a vertical arrow after about $N=200$ cycles), Figure 12(b) shows the development of misorientations, as measured by the broadening of X-ray rocking curves for reflections of type $\{200\}$ as a function of number of cycles. It is important to note that saturation of the broadening is observed about a factor of 10 later than mechanical cyclic saturation, namely after about 2000 cycles. Since the misorientations are essentially accommodated by GNDs, these results imply that the density of the GNDs continues to increase well beyond mechanical saturation at constant stress.

Figure 13 from the work of Polák ${ }^{[47]}$ shows the development of the torsional shear stress in copper polycrystals fatigued in torsion at $77 \mathrm{~K}$ and the corresponding changes of the electrical resisitivity $\Delta \rho_{\mathrm{el}}$ 


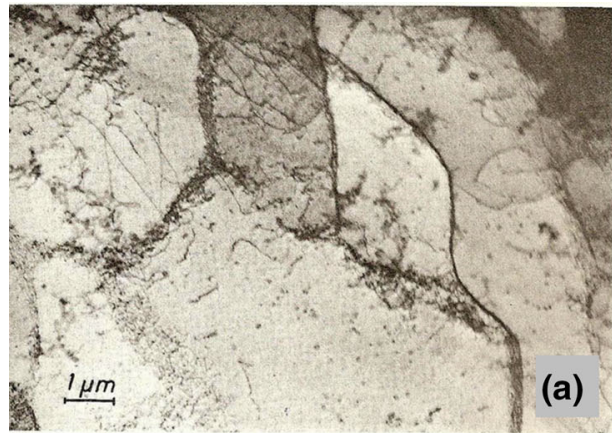

450 cycles, $\tau=53.4 \mathrm{MPa}$

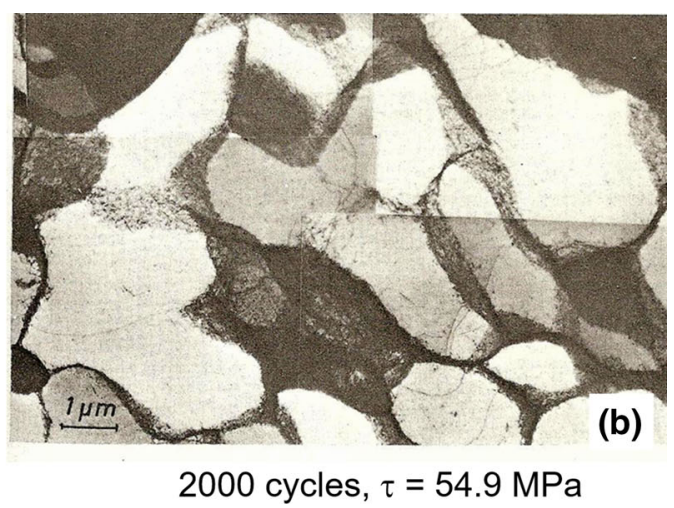

2000 cycles, $\tau=54.9 \mathrm{MPa}$

Fig. 15-TEM micrographs of the dislocation distributions in cyclically deformed $\alpha$-iron single crystals. ${ }^{[9,28]}(a)$ Early saturation. $(b)$ Deep in saturation. Reprinted with permission from Ref. [9].

as a function of number of cycles. The electrical resisitivity change $\Delta \rho_{\mathrm{el}}$ is directly proportional to the total defect density, i.e., essentially to the total density of deformation-induced dislocations and point defects. Polák showed by annealing experiments that about 50 pct of the electrical resistivity changes are due to the dislocations. Referring only to the curves for the largest amplitude in Figure 13, the following is noted. Whereas saturation of the torsional stress occurs already after about 100 cycles, the change in electrical resistivity saturates only after about 1000 cycles, i.e., a factor of 10 later. It follows that the density of defects continues to increase long after mechanical saturation has been attained.

In ferromagnetic materials like $\alpha$-iron and nickel, measurements of the coercive force $H_{\mathrm{c}}$ can be used advantageously to study the evolution of defect density. ${ }^{[24,48]}$ Since the coercive force $H_{\mathrm{c}}$ is directly proportional to $\sqrt{ } \rho,{ }^{[24]}$ it is directly proportional to the flow stress $\tau$. The cyclic saturation behavior of both $\alpha$-iron single crystals ${ }^{[24]}$ and nickel single crystals ${ }^{[48]}$ has been studied by magnetic measurements of the coercive force. In Figures 14(a) and (b), results obtained on cyclically deformed nickel single crystals are shown. It is evident that the coercive force $H_{\mathrm{c}}$ continues to increase beyond almost 2000 cycles, whereas the shear stress amplitude $\tau$ has saturated already after about 400 cycles. Quite similar results were obtained in the studies on $\alpha$-iron single crystals. ${ }^{[9,24]}$ In both cyclically deformed $\alpha$-iron single crystals and nickel single crystals, a truly microstructural steady state, characterized by attainment of a constant value of the coercive force $H_{\mathrm{c}}$, comparable to a saturation of the electrical resisitivity changes in Figure 13, was not attained. This is attributed to the fact that the number of cycles was too small. In all probability, the coercive force would have saturated, had the number of cycles been sufficiently large.

To summarize, the conclusions drawn from Figure 14, together with the similar conclusions drawn from Figure 13, and the observations that follow from Figure 12, provide proof that, in the so-called steadystate cyclic saturation, the density of the defects, essentially dislocations, continue to increase and that GNDs constitute a substantial part of the increasing dislocation density. As will be discussed in more detail in Section VII-D, it follows from the results of Polák's work on torsionally deformed copper ${ }^{[47]}$ and from the cyclic deformation studies on ferromagnetic $\alpha$-iron single crystals ${ }^{[24]}$ and nickel single crystals ${ }^{[48]}$ that the arrangement factor $\alpha$ must have decreased systematically, as the dislocation density continued to increase after mechanical steady state had been attained.

Finally, Figures 15(a) and (b) show TEM micrographs of the dislocation distribution in cyclically deformed $\alpha$-iron single crystals ${ }^{[28]}$ in early saturation and in deep saturation, respectively. These micrographs document that, during continued cycling deeper in saturation, the cell boundaries become sharper, and the overall dislocation density and the misorientations (which are indicative of GNDs) increase. This finding matches the conclusions drawn earlier from Figures 12, 13, and 14 and confirms that, at more or less constant stress, non-negligible microstructural changes occur and persist. The explanation follows along similar lines as explained earlier in Section VI-C in the case of high-temperature creep.

\section{Explanation of Constancy of Flow Stress During Simultaneous Increase of Dislocation Density}

Referring again to the flow-stress equation, Eq. [1]:

$$
\tau=\alpha \mathrm{Gb} \sqrt{ } \rho,
$$

the simultaneous constancy of both $\tau$ and $\rho$, can only be explained as follows:

(a) either $\alpha=$ const., and $\rho=$ const. (trivial!)

(b) or $\rho$ has increased, while $\alpha$ has decreased as a result of a change in the dislocation arrangement.

Since the first case is trivial, the second case, i.e., a decrease of the arrangement factor $\alpha$ as a result of a change of the dislocation arrangement, is more probable and considered realistic and will be considered in more detail subsequently. 
D. Semi-quantitative Estimate of the Decrease of the $\alpha$-Factor in Mechanical Cyclic Saturation

The decrease of the arrangement factor $\alpha$ during mechanical saturation can be estimated as follows. In the case of Polák's measurements of the electrical resisitivity of copper deformed in torsion at $77 \mathrm{~K},{ }^{[47]}$ the electrical resistivity continued to increase after the shear stress had already become constant (mechanical saturation) by about 55 pct until it reached a constant value (microstructural saturation). Since this increase is proportional to the dislocation density $\rho$, it follows that $\alpha$ must have decreased by a factor $1 / \sqrt{ } 1.55$, i.e., from the initial value $\alpha \approx 0.4$ to $\alpha \approx 0.32$.

In a similar fashion, the decrease of $\alpha$ can be estimated also, based on the change of the coercive force $H_{\mathrm{c}}$ in the cases of cyclically deformed nickel and $\alpha$-iron single crystals. In this case, the coercive force $H_{\mathrm{c}}$ increased by $\approx 50$ pct in cyclic "mechanical" saturation, hence, $\alpha$ must have decreased accordingly. Since $H_{\mathrm{c}}$ is proportional to $\sqrt{ } \rho, \alpha$ must have decreased by a factor of $1 / 1.5$, i.e., from $\alpha \approx 0.4$ to $\alpha \approx 0.27$. Within the limits of this crude estimate, this result is in satisfactory agreement with the values found above, based on electrical resisitivity measurements.

These estimates are of necessity only approximate. Nonetheless, it can be concluded that the arrangement factor $\alpha$ decreases non-negligibly by 20 pct or more with increasing deformation (and increasing heterogeneity) in cyclic saturation in the so-called steady state. The qualitative agreement of this behavior with the predictions of the composite model (Section V-B) is gratifying. Moreover, it should be noted that the present results for cyclic deformation are in line with the findings in the case of high-temperature creep, Table I. It is concluded that the heterogeneity of the dislocation distribution has an appreciable effect on the flow stress and that this has hitherto been overlooked.

\section{SUMMARY OF PERSISTENT MICROSTRUCTURAL CHANGES DURING "MECHANICAL" STEADY-STATE DEFORMATION IN BOTH HIGH-TEMPERATURE CREEP AND IN CYCLIC DEFORMATION IN SATURATION}

First, it is noted that the persistent microstructural changes that continue to occur in both the so-called steady-state high-temperature creep, defined by constant strain rate, and in steady-state cyclic saturation, defined by the constancy of the stress amplitude during strain-controlled cyclic deformation, are very similar or even identical. In both cases, the following microstructural changes continue persistently:

(a) The dislocation arrangement undergoes continuous changes.

(b) The lattice misorientations $\theta$ across the cell boundaries continue to increase, indicative of an increasing content of GNDs.

(c) The overall dislocation density $\rho$, with an appreciable GND content, continues to increase. (d) The $\alpha$-factor decreases systematically from a starting value of $\alpha \approx 0.4$ by about 20 pct or more with increasing cyclic or monotonic creep deformation.

There is one important difference between the two cases of the so-called steady-state deformation that must be noted. In tensile high-temperature creep, a truly microstructural steady state is usually not attained, simply because the creep strains to failure (in the order of only up to some $10 \mathrm{pct}$ ) are too small. In contrast, in steady-state cyclic deformation, after a very large number of cycles, very high cumulative plastic strains of the order of 10 can be reached. For this reason, a truly microstructural steady state can be attained after a sufficiently large number of cycles, as documented in Figures 12 and 13.

\section{VALIDITY OF EMPIRICAL RELATIONSHIPS BETWEEN FLOW STRESS AND MICROSTRUCTURAL PARAMETERS}

An important conclusion of the preceding considerations is that, in quasi-stationary deformation, at a particular stress, the dislocation microstructure lags behind the microstructure that would develop under truly steady-state conditions (mechanically and microstructurally). If one considers on the other hand a material that has been deformed under non-steadystate conditions at different temperatures to a particular stress, one could expect that the microstructure would lag behind the microstructure that would have developed under truly steady-state conditions. Somewhat surprisingly, a large body of experimental evidence indicates, in first approximation and within the scatter, that in both cases the dislocation density and the cell/subgrain sizes depend in much the same way on the stress, especially if the stress is corrected for the temperature dependence of the elastic constants, as probably first shown by Pratt. ${ }^{[49]}$ As discussed in more detail earlier, ${ }^{[8]}$ based on a large number of related studies, referring to high-temperature creep deformation, ${ }^{[50]}$ cyclic deformation, ${ }^{[51,52]}$ and tensile straining at constant strain rate, ${ }^{[33]}$ the shear flow stress $\tau$ in all these cases is usually related to the cell/subgrain size $d$ as follows:

$$
\tau \approx C \frac{G b}{d^{m}},
$$

where $C$ is a constant. The exponent $m$ is frequently about 1 and the constant $C$ about 10 . In some cases, especially in the case of stronger boundaries/cell walls, lower values of $m$ like 0.5 (corresponding to a HallPetch type hardening) have been found. ${ }^{[5]}$ It is interesting to note that Mandigo ${ }^{[55]}$ was able to show for a variety of materials deformed under widely different conditions, that the dislocation densities $\rho$ and the cell sizes $d$ are always related as follows:

$$
d \approx B \cdot \rho^{-1 / 2},
$$


where $B$ is a constant. Combining Eq. [18] with $m=1$ and Eq. [19], the Taylor flow-stress law (Eq. [1]) is obtained. All of the above relations are similar to those obtained by Staker and Holt for tensile-deformed copper. [53]

The important conclusion is that, irrespective of the type and details of deformation, the semi-empirical relationships (1), (15), (18), and (19) are usually obeyed at least approximately, even when the data are not obtained in steady-state deformation, as discussed in more detail earlier. ${ }^{[8]}$ While these considerations show that the above empirical laws are able to describe the gross features of the dislocation pattern, it is also clear that they are unable to capture the more subtle microstructural details that evolve in the transition from mechanical to microstructural steady state, as discussed in this work. Finally, it is noted that Eq. [18], with $m=1$, is actually the "law of similitude", according to which the dimensions of a given dislocation pattern simply shrink inversely to the stress, as introduced by Kuhlmann-Wilsdorf. ${ }^{[56]}$

\section{MAJOR CONCLUSIONS AND IMPLICATIONS}

\section{A. Definitions of Mechanical, Microstructural, and Quasi-stationary Deformation}

The preceding analysis and discussion of available published work on both high-temperature creep and also cyclic deformation in saturation have provided clear evidence for persisting ongoing microstructural changes in the so-called steady-state deformation. Thus, correctly speaking, what is commonly called steady-state deformation should in fact be referred to as quasi-stationary deformation. In general, this comprises the initial attainment of a mechanical steady state and, finally, also a microstructural steady state with a "constant" microstructure, characterized by a dynamic equilibrium between the production and annihilation of microstructural defects.

\section{B. Rectification of Basic Assumptions and Statements}

It follows from the preceding survey of experimental details and the discussion that a correct description of the transition to a steady-state deformation must address the following aspects:

(1) The quasi-stationary nature of the deformation must be considered.

(2) This implies that a distinction must be made between the initial attainment of a mechanical steady state and the transition to a final microstructural steady state.

(3) In mechanical steady state, the dislocation density is not constant but continues to increase, i.e., $\dot{\rho}^{+}>$ $\dot{\rho}^{-}$.

(4) Only later, in the approach to a truly microstructural steady state, the dislocation density tends to a constant value, resulting from a balance between the production and annihilation of dislocations. In this case, $\dot{\rho}^{+}=\dot{\rho}^{-}$, Eq. [12].

(5) As shown and explained, future analysis of the so-called steady-state deformation, or more precisely quasi-stationary deformation, must consider that the arrangement factor $\alpha$ is not a constant but decreases noticeably (by about 20 pct) during mechanical steady-state deformation, as a result of increasing heterogeneity of the dislocation distribution. This finding is supported by the fact that the dislocation density increases, although the stress is constant (Sections VI-B and VII-A, VII-C) and is in line with the predictions of the composite model, when the dislocation distribution becomes more heterogeneous (Sections IV-B and VII-B).

\section{Implications with Regard to Future Work and Dislocation Modeling of Plastic Deformation}

The present analysis has provided evidence of details of the microstructural evolution that occur during quasi-stationary deformation. These details have been overlooked and/or ignored in earlier work. Thus, in a more rigorous approach, the following changes and details in the evolution of the dislocation microstructure at constant stress (!) deserve more attention and should be considered explicitly, where necessary:

(a) The continuous increase of the overall dislocation density $\rho$, with an appreciable GND content.

(b) The continuous increase of lattice misorientations $\theta$ across the cell walls/boundaries, accommodated by an increasing content of GNDs.

(c) The marked effect of the heterogeneity of the dislocation distribution, which is reflected during quasi-stationary cyclic and high-temperature creep deformation in a systematic decrease of the arrangement factor $\alpha \approx 0.4$ by about $20 \mathrm{pct}$ with increasing heterogeneity.

Current flow-stress laws, in which it is assumed that the arrangement factor $\alpha$ is constant, are inadequate to describe satisfactorily all details of the microstructural evolution and the stress-strain behavior. As discussed earlier, the simple Taylor flow-stress law could be retained in a formal sense, if one used adjusted "effective" values of the $\alpha$-factor. ${ }^{\text {[9] }}$ However, it would be much more satisfactory, if refined flow-stress laws and microstructure-based constitutive equations were developed which consider explicitly the interaction of different slip systems and take into account the effects of heterogeneity (patterning).

Considering the impressive progress made in dislocation modeling, analytically or by 3D Discrete Dislocation Dynamics (DDD) $)^{[21,22,57-60]}$ some years ago and also very recently, ${ }^{[61,62]}$ it is hoped that eventually it will be possible to model in some detail the specific microstructural features of plastic deformation which are revealed in experiment, including the evolution of the $\alpha$-factor, during monotonic and/or cyclic hardening 
or softening, and also in quasi-stationary deformation. Then, with this capability, dislocation modeling could become a predictive tool rather than only a technique that strives in many cases just to confirm and/or reproduce what is known from experiment.

\section{ACKNOWLEDGMENTS}

Open Access funding provided by Projekt DEAL. The author acknowledges numerous fruitful discussions with many colleagues over the years and wishes to express his gratitude in particular to his colleague Wolfgang Blum.

\section{OPEN ACCESS}

This article is licensed under a Creative Commons Attribution 4.0 International License, which permits use, sharing, adaptation, distribution and reproduction in any medium or format, as long as you give appropriate credit to the original author(s) and the source, provide a link to the Creative Commons licence, and indicate if changes were made. The images or other third party material in this article are included in the article's Creative Commons licence, unless indicated otherwise in a credit line to the material. If material is not included in the article's Creative Commons licence and your intended use is not permitted by statutory regulation or exceeds the permitted use, you will need to obtain permission directly from the copyright holder. To view a copy of this licence, visit http://creat ivecommons.org/licenses/by/4.0/.

\section{REFERENCES}

1. W.A. Backofen: Deformation Processing, Addison-Wesley Pub. Co., London, 1972, p. 227.

2. P. Montmitonnet: Materials Processing and Design, Modeling, Simulation and Applications, NUMIFORM '07: 9th International Conferenceon Numerical Methods in Industrial Forming Processes, 2007, pp. 209-14.

3. R. Pippan, S. Scheriau, A. Taylor, M. Hafok, A. Hohenwarter, and A. Bachmaier: Annu. Rev. Mater. Res., 2010, vol. 40, pp. 319-43.

4. O. Renk, A. Hohenwarter, S. Wurster, and R. Pippan: Acta Materialia, 2014, vol. 77, pp. 401-10.

5. M.D. Zoback, J. Townsend, and B. Grollimund: Int. Geol. Rev., 2002, vol. 44, pp. 383-401.

6. K. Wang, V. Hu, and J. He: Nature, 2012, vol. 484, pp. 327-32.

7. S. Hawking: A Brief History of Time: From the Big Bang to Black Holes, Bantam Books, New York, 1988

8. H. Mughrabi: Z. Metallkde, 2005, vol. 96, pp. 546-51.

9. H. Mughrabi: Curr. Opin. Solid State Mater. Sci., 2016, vol. 20, pp. 411-420.

10. W. Blum: Private communication, and Materials Science and Technology, Plastic Deformation and Fracture, R.W. Cahn, P. Haasen, E.J. Kramer, eds., H. Mughrabi, VCH, Weinheim, 1993, vol. 6 , pp. 361-405.

11. C. Laird: in Dislocations in Solids, vol. 6, F.R.N. Nabarro, ed. North-Holland Publishing Company, 1983, pp. 57-120.

12. H. Mughrabi: Dislocations and Properties of Real Materials (Conf. Proc.), Book No. 323, The Institute of Metals, London, 1984, pp. 244-60.
13. S. Suresh: Fatigue of Materials, 2nd ed., Cambridge University Press, Cambridge, 1998.

14. W. Blum, J. Dvořák, P. Král, P. Eisenlohr, and V. Sklenička: $J$. Mater. Sci., 2014, vol. 49, pp. 2987-97.

15. W. Blum, J. Dvořák, P. Král, P. Eisenlohr, and V. Sklenička: $J$. Mater. Sci. Technol., 2015, vol. 31, pp. 1065-68.

16. Y. Huang: IOP Conf. Ser., 2017, vol. 219, pp. 1-8.

17. L.P. Kubin: Materials Science and Technology in Plastic Deformation and Fracture, R.W. Cahn, P. Haasen, E.J. Kramer, eds., H. Mughrabi, VCH, Weinheim, 1993, vol. 6, pp. 137-90.

18. G.I. Taylor: Proc. R. Soc. Lond., 1934, vol. 145, pp. 362-87.

19. G. Saada: Acta Metallurgica, 1960, vol. 8, pp. 841-47.

20. G. Schoeck and R. Frydman: Physica Status Solidi B, 1972, vol. 53, pp. 661-673.

21. B. Devincre, T. Hoc, and L. Kubin: Science, 2008, vol. 320, pp. $1745-48$

22. L.P. Kubin, B. Devincre, and T. Hoc: Mater. Sci. Eng. A, 2008, vols. $483-484$, pp. $19-24$

23. M. Sauzay and L.P. Kubin: Progr. Mater. Sci., 2012, vol. 56, pp. $725-84$.

24. H. Mughrabi, R. Kütterer, K. Lubitz, and H. Kronmüller: Phys. Status Solidi A, 1976, vol. 38, pp. 261-70.

25. H. Mughrabi, T. Ungár: Dislocations in Solids, vol. 11, F.R.N. Nabarro and S. Duesberry, eds., Elsevier Science Elsevier Science, 2002, pp. 343-411.

26. H. Mughrabi: Philos. Mag., 1971, vol. 23, pp. 897-929.

27. H. Mughrabi, T. Ungár, W. Kienle, and M. Wilkens: Philos. Mag., 1986, vol. 53, pp. 793-813.

28. H. Mughrabi, K. Herz, and X. Stark: Int. J. Fract., 1981, vol. 17, pp. 193-320.

29. H. Mughrabi, R. Wang: Deformation of Polycrystals: Mechanisms and Microstructures, Proceedings of 2nd Risoe International Symposium, N. Hansen ed., 1981, pp. 87-98.

30. M.E. Kassner, A.A. Ziaai-Moayyed, and A.K. Miller: Met. Trans. A, 1985, vol. 16A, pp. 1069-1076.

31. F. Petry and F. Pschenitzka: Mater. Sci Eng., 1984, vol. 68, pp. L7-L11.

32. H. Mughrabi: Acta Metallurgica, 1983, vol. 31, pp. 1367-79.

33. H. Mughrabi: Mater. Sci. Eng., 1987, vol. 85, pp. 5-31.

34. Z.S. Basinski: Scripta metallurgica, 1974, vol. 8, pp. 1301-08.

35. A.H. Cottrell: Dislocations and Plastic Flow in Crystals, Oxford University Press, Oxford, 1953, p. 208

36. A. Seeger: Philos. Mag., 1954, vol. 45, pp. 771-73.

37. M.E. Kassner and M.-T. Pérez-Prado: Progr. Mater. Sci., 2000, vol. 45 , pp. $1-102$.

38. M.E. Kassner, J.W. Elmer, and C.J. Echer: Metall. Trans. A, 1986, vol. 17, pp. 2093-97.

39. M.E. Kassner and M.E. McMahon: Metall. Trans. A, 1987, vol. 18, pp. 835-46.

40. M.F. Ashby: Philos. Mag., 1970, vol. 21, pp. 399-424.

41. H. Mughrabi: Mater. Sci. Eng. A, 2001, vol. 317, pp. 171-80.

42. J. Weertman: Proceedings of 20th Risoe International Symposium on Materials Science, N. Hansen, D. Juul-Jensen, T. Leffers, W. Pantleon, O.B. Pedersen, G. Winther, eds., Roskilde, Denmark, 1999, pp. 201-12.

43. R. Wang, H. Mughrabi, S. McGovern, and M. Rapp: Mater. Sci. Eng., 1984, vol. 65, pp. 219-33.

44. R. Wang and H. Mughrabi: Mater. Sci. Eng., 1984, vol. 63, pp. 147-63.

45. H. Mughrabi, F. Ackermann and K. Herz: Fatigue Mechanisms, Proc. of an ASTM-NBS-NF Symposium, J.T. Fong, ed., ASTM-STP 675, American Society for Testing and Materials, Philadelphia, 1979, pp. 69-105.

46. M. Wilkens, K. Herz, and H. Mughrabi: Z. Metallkde, 1980, vol. 96 , pp. $546-51$.

47. J. Polák: Czech J. Phys., 1969, vol. 19, pp. 315-22.

48. W. Wolf: Untersuchungen der Versetzungsanordnung wechsel- und zugverformter Nickel-Einkristalle mit Hilfe magnetischer Methoden. Technische Hochschule Stuttgart, Doctorate Thesis: 1980.

49. J. Pratt: Acta Metall., 1967, vol. 15, pp. 319-27.

50. S.V. Raj and G.M. Pharr: Mater. Sci. Eng., 1986, vol. 81, pp. 217-37.

51. C.E. Feltner and C. Laird: Acta Metall., 1967, vol. 15, pp. $1621-32$

52. R.C. Daniel and G.T. Horne: Metall. Trans., 1971, vol. 2, pp. 1161-1172. 
53. M.R. Staker and D.L. Holt: Acta Metall., 1972, vol. 20, pp. 569-79.

54. D.J. Abson and J.J. Jonas: Met. Sci. J., 1970, vol. 4, pp. 24-28.

55. F.N. Mandigo: Ph. D. Thesis, Cornell University, 1972.

56. D. Kuhlmann-Wilsdorf: Met. Soc. AIME., 1962, vol. 224, pp. 1047-61.

57. S. Groh and H.M. Zbib: J. Eng. Mater. Technol, 2009, vol. 131, p. 041209.

58. M. Fivel and C. Déprés: Philos. Mag., 2014, vol. 94, pp. 3206-14.

59. G. Po, M.S. Mohamed, T. Crosby, C. Erel, A. El-Azab, and N. Ghoniem: JOM, 2014, vol. 66, pp. 2108-20.
60. S.X. Xia and A. El-Azab: IOP Conf. Ser., 2015, vol. 89 (012053), pp. $1-9$.

61. C. Erel, G. Po, and N. Ghoniem: Philos. Mag., 2017, vol. 97, pp. 2897-2970.

62. S. Papanikolaou, Y. Cui, N. Ghoniem: Modelling and Simulation in Materials Science and Engineering, vol. 26, No. 1, Focus on MMM 2016.

Publisher's Note Springer Nature remains neutral with regard to jurisdictional claims in published maps and institutional affiliations. 